\title{
Assessment of Wind Power Potential Based on Raleigh Distribution Model: An Experimental Investigation for Coastal Zone
}

\author{
Bisharatullah Memon \\ Department of Electrical Engineering, \\ Mehran University of Engineering \& \\ Technology, Sindh, Pakistan
}

\section{Sajid H. Qazi}

Department of Electrical Engineering, Mehran University of Engineering \& Technology, Sindh, Pakistan

\author{
Mazhar H. Baloch \\ Department of Electrical Engineering, \\ Mehran University of Engineering \& \\ Technology, Sindh, Pakistan
}

\section{Raza Haider}

Electrical Engineering Department, Baluchistan University of Engineering \& Technology, Khuzdar, Pakistan

\begin{abstract}
A. Hakeem Memon
Department of Electrical Engineering, Mehran University of Engineering \&

Technology, Sindh, Pakistan
\end{abstract}

Dahaman Ishak

School of Electrical and Electronics Engineering, Universiti Sains Malaysia, Malaysia

\begin{abstract}
The wind energy share in the global energy production is increasing rapidly. Currently, the Government of Pakistan (GoP) is moving towards renewable energy resources (RER), specifically wind and solar energy. In this paper, the wind energy potential of Tando Ghulam Ali, Sindh, Pakistan is explored. For this purpose, one-year wind speed data are considered at various heights through various probability distribution functions (PDFs). Statistical comparison of Rayleigh, gamma, generalized extreme value (GEV) and lognormal PDFs have been done with two methods, namely root mean square error and $\left(R^{2}\right)$ in order to select the best PDF. Results showed that the Rayleigh distribution function is the best at the above area for finding various factors like site selection and wind power cost per $\mathrm{kWh}$.
\end{abstract}

Keywords-wind energy; wind probability distribution function; fitting tool

\section{INTRODUCTION}

Several countries are investing resources in the direction of RER. Energy sources like biomass, wind energy, hydro energy, and thermal energy have gained interest because of their friendly environment features [1, 21-23]. The wind energy is a drifting RER for production of energy, and can have better results over the reliability and stability of the power system. Wind power recorded a yearly development of $25 \%$ rate over the past few years $[2,20]$ and is based on the wind speed estimation, which is uncertain in considering wind energy and the performance of the wind energy conversion system. Wind speed at a location diverges unsystematically and its deviation in a specific area over a time period and can be characterized by PDFs. Several PDFs are taken to estimate the wind speed features including Rayleigh, Weibull, GEV, lognormal and gamma [3]. To find the most accurate of PDFs, prediction performance tests are suggested. In this paper, root mean square error (RMSE) and coefficient of determination $\left(\mathrm{R}^{2}\right)$ tests are considered.
In [4], it was shown that the outcomes of the Weibull distribution dignified the PDF and are more suitable as compared to the Rayleigh distribution in the peak height region of Nepal [4]. Authors in [5] ranked 7 different methods considering the examined error of calculations regarding wind energy. Authors in [6] found the wind power density in a specific location of Pakistan at various heights and considered different distribution functions for wind speed calculation and from 5 numerical methods. Authors in [7] examined the comparison between the lognormal and Weibull techniques by fitting the curve of observed wind speeds and concluded that the Weibull distribution is more reliable than lognormal distribution to pronounce the performance of wind speed data. Authors in [8] explored the number of distribution techniques to find the exact wind speed data in Hong Kong. This study summarizes the results of wind speed data at Tando Ghulam Ali. This study tries to find the best distribution techniques from various PDFs like: Rayleigh, gamma, GEV and lognormal. From the results, it was proved that the Rayleigh distribution function was the best distribution technique for the studied site.

\section{MATHEMATICAL PDFS}

The estimation of wind energy at a particular site involves statistical methods of PDF, which require wind speed data at a meteorological station. Similarly, frequency distribution functions are used to estimate wind power density. Some types of PDFs are chi-squared distribution, Rayleigh distribution, generalized normal, three parameter log-normal, log normaldistribution, gamma distribution, kappa, wake by inverse Gaussian distribution, normal two variable distributions, hybrid distribution, as well as normal square root of wind speed distribution [9-11]. 


\section{A. Rayleigh Distribution Model}

Rayleigh distribution function [12]:

$$
f(v)=\frac{2 v}{c^{2}} \exp \left(-\frac{v}{c}\right)^{2}
$$

The shape parameter $(k)$ is assumed to be 2 and the scale parameter $(c)$ is defined as:

$$
c=\frac{m}{\Gamma\left(1+\frac{1}{k}\right)}
$$

where $(m)$ is the mean and can be obtained as:

$$
m=\frac{1}{N} \sum_{i=1}^{N} v i
$$

B. Gamma Distribution Model

The gamma distribution function can be defined as [13]:

$$
f(v)=\frac{v^{\alpha-1}}{\beta^{\alpha} \Gamma(\alpha)} \exp \left[-\frac{v}{\beta}\right]
$$

where,

$$
\begin{aligned}
& \alpha=\frac{m^{2}}{s^{2}} \\
& \beta=\frac{s^{2}}{m}
\end{aligned}
$$

where $(s)$ can be obtained as follows:

$$
s=\left[\frac{1}{N-1} \sum_{i=0}^{N}(v i-m)^{2}\right]^{\frac{1}{2}}
$$

\section{Lognormal Distribution Model}

Lognormal distribution can be defined as [14]:

$$
f(v)=\frac{1}{v \beta \sqrt{2 \pi}}\left[-\frac{1}{2}\left(\frac{(\ln \ln (v)-\alpha)}{\beta}\right)^{2}\right]
$$

Parameters from (8) are estimated as:

$$
\begin{aligned}
& \alpha=\ln \ln \left[\frac{m}{\sqrt{1+\frac{s^{2}}{m^{2}}}}\right] \\
& \beta=\sqrt{\ln \ln \left(1+\frac{s^{2}}{m^{2}}\right)}
\end{aligned}
$$

\section{Generalized Extreme Value Distribution (GEV) Model}

It is a combination of Frechet, Gumbel and Weibull maximum extreme value distributions and can be defined as [15]:

$$
f(v)=\frac{1}{\alpha}\left[1-\frac{k}{\alpha}(v-\mu)\right]^{\frac{1}{k}-1}\left\{-\left[1-\frac{k}{\alpha}(v-\mu)\right]^{\frac{1}{k}}\right\} \text { if } k \neq 0
$$

With the support of the maximum likelihood method, the parameters of GEV can be obtained as:

$$
L L=\ln \prod_{i=1}^{n}\left\{e\left(v_{i} ; \zeta, \delta, l\right)\right\}=\sum_{i=l \ln }^{n}\left\{e\left(v_{i} ; \zeta, l\right)\right\}
$$

\section{PROBABILITY DISTRIBUTION MODEL EVALUATION}

In this paper, for the initial evaluation of the process the graphical display of the wind speed of measured data is being superimposed by the fitted PDFs and visual comparison is done. RMSE and $\mathrm{R}^{2}$ criteria are considered for choosing the appropriateness of the fit method for the selected three functions along with their ability to estimate the energy and to predict the wind potential. The performance of these functions is analyzed through the following ways [16]:

\section{A. Root Mean Square Error (RMSE)Test}

The value of RMSE that is nearest to the zero indicates a better distribution function. The RMSE is calculated as [17]:

$$
R M S E=\frac{1}{N} \sum_{I=0}^{N}(p i-f i)^{2}
$$

B. $R^{2}$ Test

The R-squared goodness of fit test is hypothesis and comparison testing that determines the correlation between the predicted and observed data. Greater value of $\mathrm{R}^{2}$ shows better fit of the PDF. It can be defined as [18]:

$$
R^{2}=1-\frac{\sum_{i=1}^{N}(p i f i)^{2}}{\sum_{I=1}^{N}(\text { pipi })^{2}}
$$

\section{Wind Power Density Function}

It is defined as the power generated by wind turbine per $\mathrm{m}^{2}$. It is helpful in the estimation of wind resources at a site. There are many ways to determine wind power density [6], and it can be defined as follows:

$$
W P D=\sum_{i=1}^{N} \frac{1}{2} \rho v i^{3} f(v i)
$$

where the probability of wind speed at the i-th speed value is $f(v i)$. The standard value of air density is considered to be $\rho=1.225 \mathrm{~kg} / \mathrm{m}^{3}$.

\section{RESULTS AND DISCUSSION}

The proposed site, Tando Ghulam Ali located near Hyderabad, Sindh province, lies in the southern region of Pakistan, at $24^{\circ} 52^{\prime} 02.025^{\prime} ' \mathrm{~N}$ and $66^{\circ} 51^{\prime} 41.983^{\prime}$ 'E. One year's wind speed data (from Jan 2017 to Dec 2017), with 10 minute sample intervals were used. The typical hourly and monthly measurements are calculated at the different heights of 80,60, 40 and $20 \mathrm{~m}$. The average wind speed at different heights is shown in Figure 1(a-b). Table I summarizes the average values of wind speed and wind power density for all heights.

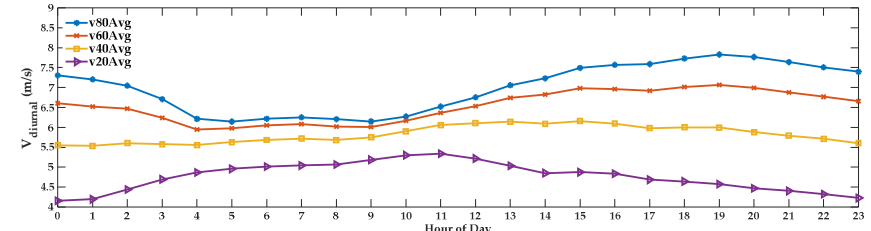

(a)

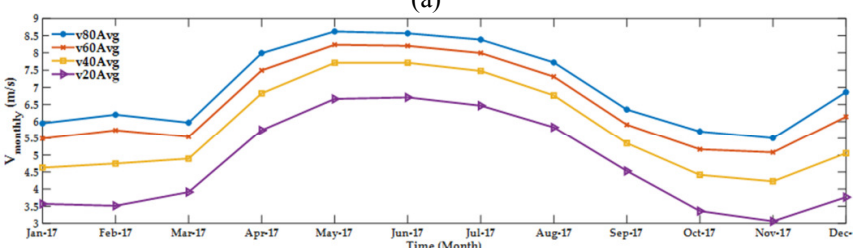

(b)

Fig. 1. (a) Hourly and (b) monthly average wind speed at different heights. 
TABLE I. MONTHLY AVERAGE OF WIND SPEED AND WIND POWER DENSITY

\begin{tabular}{|c|c|c|c|c|c|c|c|c|}
\hline Heights & \multicolumn{2}{|c|}{$80 m$} & \multicolumn{2}{|r|}{$60 m$} & \multicolumn{2}{|r|}{$40 \mathrm{~m}$} & \multicolumn{2}{|r|}{$20 \mathrm{~m}$} \\
\hline Months/Factors & $\mathrm{V}_{\text {avg }}(\mathrm{m} / \mathrm{s})$ & WPD(Watts/m²) & $V_{\text {avg }}(\mathrm{m} / \mathrm{s})$ & WPD (Watts $/ \mathbf{m}^{2}$ ) & $\mathbf{V}_{\text {avg }}(\mathrm{m} / \mathrm{s})$ & WPD (Watts/m²) & $\mathrm{V}_{\text {avg }}(\mathrm{m} / \mathrm{s})$ & WPD (Watts/m $\left.\mathbf{m}^{2}\right)$ \\
\hline Jan & 5.948 & 199.339 & 5.492 & 146.349 & 4.631 & 83.229 & 3.568 & 40.876 \\
\hline Feb & 6.201 & 241.862 & 5.743 & 178.793 & 4.753 & 93.854 & 3.513 & 39.094 \\
\hline Mar & 5.967 & 188.372 & 5.546 & 147.580 & 4.897 & 102.387 & 3.913 & 55.409 \\
\hline Apr & 7.999 & 394.927 & 7.491 & 326.331 & 6.824 & 254.450 & 5.745 & 160.253 \\
\hline May & 8.623 & 449.674 & 8.238 & 396.278 & 7.712 & 330.572 & 6.662 & 216.206 \\
\hline June & 8.568 & 485.264 & 8.206 & 431.087 & 7.714 & 365.560 & 6.708 & 245.574 \\
\hline Jul & 8.385 & 464.414 & 7.997 & 408.468 & 7.475 & 340.660 & 6.466 & 224.809 \\
\hline Aug & 7.723 & 362.365 & 7.309 & 312.404 & 6.764 & 254.442 & 5.831 & 168.981 \\
\hline Sep & 6.351 & 181.119 & 5.908 & 146.452 & 5.353 & 112.059 & 4.534 & 71.889 \\
\hline Oct & 5.705 & 166.097 & 5.171 & 114.592 & 4.418 & 67.361 & 3.358 & 30.346 \\
\hline Nov & 5.506 & 176.713 & 5.082 & 128.415 & 4.230 & 66.299 & 3.057 & 23.446 \\
\hline Dec & 6.859 & 271.994 & 6.141 & 181.989 & 5.056 & 97.521 & 3.765 & 42.218 \\
\hline Year & 6.990 & 3.010 .112 & 6.531 & 243.228 & 5.824 & 184.041 & 4.767 & 103.934 \\
\hline
\end{tabular}

(a)

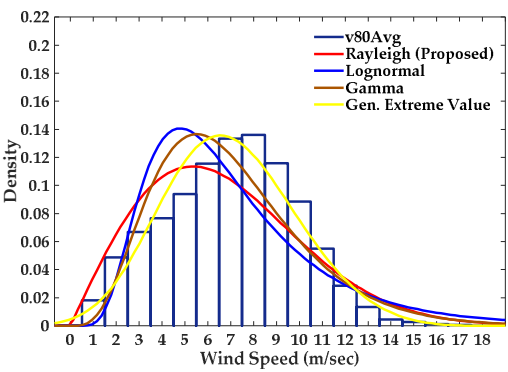

(b)

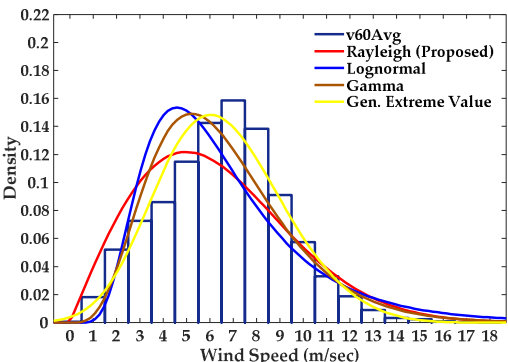

(c)

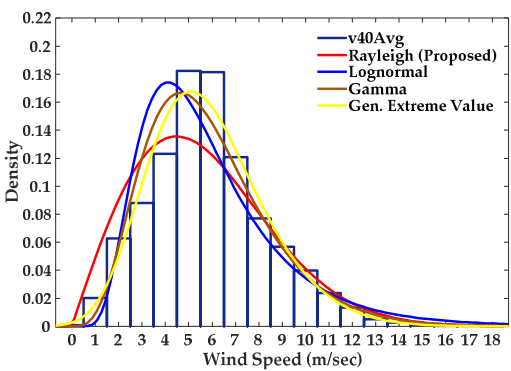

(d)

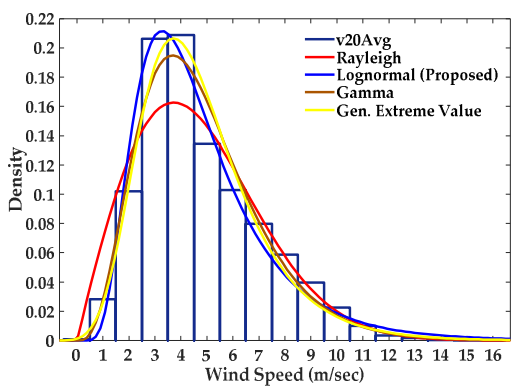

Fig. 2. Fitting of different PDFs over the data using MATLAB distribution fitting tool.
Figure 2 shows the fitting of each PDF over the data. It can be observed that for $80 \mathrm{~m}, 60 \mathrm{~m}$, and $40 \mathrm{~m}$, the Rayleigh distribution fitted best, followed by gamma, generalized extreme value and lognormal. Due to the lower wind speed at $20 \mathrm{~m}$, lognormal fitted best followed by Rayleigh, gamma and generalized extreme value. Table II shows the value of the parameters for each PDF. Table III shows the statistical errors for the different distribution functions and the value of both RMSE and $\mathrm{R}^{2}$ goodness of fit tests. For economical evaluation the cost of each turbine is considered as $\$ 1.5 / \mathrm{W}$, other initial costs like transportation, installation, grid integration etc. are taken as $40 \%$ of the turbine's cost, the cost of the maintenance and operations is $1.5 \%$ of the turbine's cost at interest rate of $10 \%$ and the turbine life span is taken as 20 years.

TABLE II. PARAMETERS OF DIFFERENT PDFS

\begin{tabular}{|c|c|c|c|c|c|}
\hline PDF & & $\mathbf{2 0 m}$ & $\mathbf{4 0 m}$ & $\mathbf{6 0 m}$ & $\mathbf{8 0 m}$ \\
\hline \multirow{2}{*}{ Rayleigh } & $k$ & 2 & 2 & 2 & 2 \\
\cline { 2 - 6 } & $c$ & 3.7314 & 4.4750 & 4.9820 & 5.3376 \\
\hline \multirow{2}{*}{ Gamma } & $\alpha$ & 4.402 & 4.9230 & 4.9692 & 4.72186 \\
\cline { 2 - 6 } & $\beta$ & 1.082 & 1.1832 & 1.3144 & 1.4805 \\
\hline \multirow{3}{*}{ GEV } & $K$ & 0.00223 & -0.1254 & -0.19450 & -0.2173 \\
\cline { 2 - 6 } & $A$ & 1.7813 & 2.2135 & 2.5327 & 2.7809 \\
\cline { 2 - 6 } & $l$ & 3.7259 & 4.7945 & 5.49120 & 5.8888 \\
\hline \multirow{2}{*}{ Lognormal } & $\alpha$ & 1.443 & 1.6571 & 1.7727 & 1.8350 \\
\cline { 2 - 6 } & $\beta$ & 0.506 & 0.4932 & 0.5001 & 0.5172 \\
\hline
\end{tabular}

TABLE III. STATISTICAL ERRORS AT EACH HEIGHT

\begin{tabular}{|c|c|c|c|}
\hline Height & Method & RMSE & $\mathbf{R}^{\mathbf{2}}$ \\
\hline \multirow{4}{*}{$\mathbf{8 0 m}$} & Rayleigh & 0.010418 & 0.954265 \\
\cline { 2 - 4 } & Gamma & 0.019615 & 0.840719 \\
\cline { 2 - 4 } & Gen Extreme Value & 0.019931 & 0.834948 \\
\cline { 2 - 4 } & Lognormal & 0.026673 & 0.713073 \\
\hline \multirow{4}{*}{$\mathbf{6 0 m}$} & Rayleigh & 0.010568 & 0.960678 \\
\cline { 2 - 4 } & Gamma & 0.018961 & 0.875165 \\
\cline { 2 - 4 } & Gen Extreme Value & 0.02168 & 0.841316 \\
\cline { 2 - 4 } & Lognormal & 0.02644 & 0.761952 \\
\hline \multirow{4}{*}{ 40m } & Rayleigh & 0.010357 & 0.969184 \\
\cline { 2 - 4 } & Gamma & 0.014716 & 0.937879 \\
\cline { 2 - 4 } & Gen Extreme Value & 0.021199 & 0.879976 \\
\cline { 2 - 4 } & Lognormal & 0.022046 & 0.862584 \\
\hline \multirow{3}{*}{$\mathbf{2 0 m}$} & Lognormal & 0.00994 & 0.978188 \\
\cline { 2 - 4 } & Rayleigh & 0.010305 & 0.976476 \\
\cline { 2 - 4 } & Gamma & 0.010919 & 0.972912 \\
\cline { 2 - 4 } & Gen Extreme Value & 0.01923 & 0.921165 \\
\hline
\end{tabular}




\section{PERFORMANCE AND COST ASSESSMENTS}

The investment cost of a wind power plant is extremely high, it is therefore important to estimate the cost of the energy generated by a turbine in $\$ / \mathrm{kWh}$, which can be calculated by (16) [19]:

$$
C=\frac{I}{8760 t}\left(\frac{1}{P_{R} C_{f}}\right)\left[1+m\left\{\frac{(1+i)^{t}-1}{i(1+i)^{t}}\right\}\right]
$$

where $P_{R}$ is the rated turbine power, $C_{f}$ is capacity factor, $m$ is the cost of operation and maintenance, $i$ is the rate of interest and $I$ is the investment cost. To assess the performance and economical evaluation of wind turbines at the candidature site, five different turbines were considered whose specifications are given in Table IV. Each turbine comes with different hub heights. The performance of wind turbines is taken at the hub height of $80 \mathrm{~m}$. Estimated capacity factor, annual energy output $(\mathrm{kWh} /$ year) and cost $/ \mathrm{kWh}$ in dollars, for each wind turbine are shown in Table V. The Gamesa G128/4500 wind turbine minimum cost is $\$ 0.05453$ per $\mathrm{kWh}$ of energy generated, with a capacity factor of $40.87 \%$. Nordex N90/2500 model also costs minimum at $\$ 0.05453$ per $\mathrm{kWh}$ with a capacity factor of $32.88 \%$. The highest cost of $\$ 0.08019$ per $\mathrm{kWh}$ energy generated by Vestas V112/3000 with a capacity factor of $27.78 \%$.

TABLE IV. WIND TURBINES SPECIFICATIONS

\begin{tabular}{|c|c|c|c|c|c|}
\hline Model & $\begin{array}{c}\text { Enercon } \\
\text { E82 }\end{array}$ & $\begin{array}{c}\text { Gamesa } \\
\text { G128 }\end{array}$ & $\begin{array}{c}\text { Nordex } \\
\text { N90 }\end{array}$ & $\begin{array}{c}\text { Repower } \\
\text { MM82 }\end{array}$ & $\begin{array}{c}\text { Vestas } \\
\text { V112 }\end{array}$ \\
\hline $\begin{array}{c}\text { Rated power } \\
(\mathrm{kW})\end{array}$ & 2300 & 4500 & 2500 & 2050 & 3000 \\
\hline $\begin{array}{c}\text { Rotor diameter } \\
(\mathrm{m})\end{array}$ & 82 & 128 & 90 & 82 & 112 \\
\hline Hub height (m) & 138,78 & $140,120,81$ & $\begin{array}{c}120,100, \\
80,75\end{array}$ & 100,59 & 119,84 \\
\hline $\begin{array}{c}\text { Cut-in wind } \\
\text { speed (m/s) }\end{array}$ & 2 & 1.05 & 3 & 3.5 & 3.5 \\
\hline $\begin{array}{c}\text { Rated wind } \\
\text { speed (m/s) }\end{array}$ & 14 & 12 & $13-14$ & 15 & 15.5 \\
\hline $\begin{array}{c}\text { Cut-out wind } \\
\text { speed (m/s) }\end{array}$ & 25 & 25 & 25 & 22 & 25 \\
\hline
\end{tabular}

TABLE V. ESTIMATED COST PER KWH

\begin{tabular}{|c|c|c|c|c|}
\hline $\begin{array}{c}\text { Turbine } \\
\text { Model }\end{array}$ & $\begin{array}{c}\text { Power generated } \\
(\mathbf{k W})\end{array}$ & $\begin{array}{c}\text { Energy produced } \\
\text { (MWh) }\end{array}$ & $\begin{array}{c}\text { Capacity } \\
\text { factor }\end{array}$ & $\begin{array}{c}\text { Cost/k } \\
\mathbf{W h}\end{array}$ \\
\hline Gamesa G128 & 183913.03 & 1611078.14 & 40.870 & 0.05453 \\
\hline Nordex N90 & 82216.61 & 720217.50 & 32.887 & 0.05453 \\
\hline $\begin{array}{c}\text { Repower } \\
\text { MM82 }\end{array}$ & 65076.14 & 570066.99 & 32.538 & 0.06849 \\
\hline Enercon E82 & 73937.89 & 647695.92 & 32.147 & 0.06932 \\
\hline Vestas V112 & 83367.15 & 730296.23 & 27.789 & 0.08019 \\
\hline
\end{tabular}

\section{CONCLUSION}

The study concludes that the proposed site can be utilized for commercial purpose. Government of Pakistan (GoP) can exploit this site for wind energy power generation. Four techniques, gamma distribution, Rayleigh distribution, lognormal distribution, and generalized extreme value distribution were employed and their statistical evaluation was conducted by RMSE and $\mathrm{R}^{2}$ through Matlab distribution fitting tool. The following points are concluded:
- In comparison to other PDFs, the Rayleigh distribution function fits more accurately to the wind probability distribution at higher altitudes. While at lower wind speeds, lognormal showed better fitting.

- The Gamesa G128 wind turbine model is recommended, having lower cost regarding generated energy, with highest capacity factor of $40.8 \%$.

- More feasibility study of wind power project is required, to exploit wind potential at the proposed site.

- Results showed that the highest wind potential is available during the summer season, during May-July and can be used for power generation.

Calculations were made to obtain the parameter of each PDF, and then the best fitted distribution technique was used to determine the wind potential. This site is in the premises of the National Grid which is another advantage of installing wind projects there. Finally, this site can be employed for commercial purposes.

\section{ABBREVIATIONS}

$V=$ wind speed $(\mathrm{m} / \mathrm{s})$,

$\rho=\operatorname{air}$ density $\left(\mathrm{kg} / \mathrm{m}^{3}\right)$,

$\mu=$ mean of wind speed $(\mathrm{m} / \mathrm{s})$,

$m=$ mean of wind speed $(\mathrm{m} / \mathrm{s})$

$f(v)=$ probability density function

$s=$ standard deviation

$\delta=$ scale parameter of GEV distribution $(\mathrm{m} / \mathrm{s})$,

$\beta=$ scale parameter of gamma distribution $(\mathrm{m} / \mathrm{s})$,

$\alpha=$ shape parameter of gamma distribution (dimensionless),

$k=$ shape parameter of Rayleigh distribution (dimensionless),

$c=$ scale parameter of Rayleigh distribution $(\mathrm{m} / \mathrm{s})$,

$\zeta=$ shape parameter of GEV distribution (dimensionless)

$\Phi=$ standard deviation of natural logarithm

$\Gamma=$ gamma function; $\lambda$ : mean of natural logarithm

$\mathrm{RMSE}=$ root mean square error,

$R^{2}=$ Coefficient of determination

\section{REFERENCES}

[1] M. H. Baloch, G. S. Kaloi, J. Wang, "Feasible Wind Power Potential from Costal Line of Sindh Pakistan", Research Journal of Applied Sciences, Engineering and Technology, Vol. 10, No. 4, pp. 393-400, 2015

[2] V. Sohoni, S. Gupta, R. Nema, "A comparative analysis of wind speed probability distributions for wind power assessment of four sites", Turkish Journal of Electrical Engineering \& Computer Sciences, Vol. 24, No. 6, pp. 4724-4735, 2016

[3] K. W. G. D. H. Rajapaksha, K. Perera, "Wind speed analysis and energy calculation based on mixture distributions in Narak kalliya, Sri Lanka", Journal of the National Science Foundation of Sri Lanka Vol. 44, No. 4, pp. 409-416, 2016

[4] A. Parajuli, "A statistical analysis of wind speed and power density based on Weibull and Rayleigh models of Jumla, Nepal", Energy and Power Engineering, Vol. 8, No. 7, pp. 271-271, 2016

[5] A. K. Azad, M. G. Rasul, T. Yusaf, "Statistical diagnosis of the best weibull methods for wind power assessment for agricultural applications", Energies, Vol. 7, No. 5, pp. 3056-3085, 2014

[6] S. F. Khahro, K. Tabbassum, A. M. Soomro, L. Dong, X. Liao, "Evaluation of wind power production prospective and Weibull parameter estimation methods for Babaurband, Sindh Pakistan", Energy conversion and Management, Vol. 78, pp. 956-967, 2014

[7] A. Zaharim, A. M. Razali, R. Z. Abidin, K. Sopian, "Fitting of statistical distributions to wind speed data in Malaysia", European Journal of Scientific Research, Vol. 26, No. 1, pp. 6-12, 2009 
[8] Y. Q. Xiao, Q. S. Li, Z. N. Li, Y. W. Chow, G. Q. Li, "Probability distributions of extreme wind speed and its occurrence interval", Engineering Structures, Vol. 28, No. 8, pp. 1173-1181, 2006

[9] S. H. Pishgar-Komleh, A. Keyhani, P. Sefeedpari, "Wind Speed and Power Density Analysis Based on Weibull and Rayleigh Distributions (A Case Study: Firouzkooh County of Iran)", Renewable and Sustainable Energy Reviews, Vol. 42, pp. 313-322, 2015

[10] T. B. Ouarda, C. Charron, J. Y. Shin, P. R., Marpu, A. H. Al-Mandoos, M. H. Al-Tamimi, H. Ghedira, T. N. Al Hosary, "Probability distributions of wind speed in the UAE. Energy Conversion and Management, Vol. 93, pp. 414-434, 2015

[11] P. A. C. Rocha, R. C. de Sousa, C. F. de Andrade, M. E. V. da Silva, "Comparison of seven numerical methods for determining Weibull parameters for wind energy generation in the northeast region of Brazil", Applied Energy, Vol. 89, No. 1, pp. 395-400, 2012

[12] Z. Olaofe, K. Folly, "Statistical Analysis of the Wind Resources at Darling for Energy Production", International Journal of Renewable Energy Research, Vol. 2, pp. 250-261, 2012

[13] C. Tian Pau, "Estimation of wind energy potential using different probability density functions", Applied Energy, Vol. 88, No. 5, pp. 1848-1856, 2011

[14] V. T. Morgan, "Statistical distributions of wind parameters at Sydney, Australia”, Renewable Energy, Vol. 6, No. 1, pp. 39-47, 1995

[15] Y. An, M. D. Pandey, "The r largest order statistics model for extreme windspeed estimation", Journal of Wind Engineering and Industrial Aerodynamics, Vol. 95, No. 3, pp. 165-182, 2007

[16] A. Azad, M. Rasul, T. Yusaf, "Statistical Diagnosis of the Best Weibull Methods for Wind Power Assess-ment for Agricultural Applications", Energies, Vol. 7, pp. 3056-3085, 2014

[17] S. A. Akdag, A. Dinler, "A new method to estimate Weibull parameters for wind energy applications", Energy Conversion and Management, Vol. 50, No. 7, pp. 1761-1766, 2009

[18] T. Soukissian, "Use of multi-parameter distributions for offshore wind speed modelling: the Johnson S E distribution”, Applied Energy, Vol. 111, pp. 982-1000, 2013

[19] A. Mostafaeipour, A. Sedaghat, A. A. Dehgan-Niri, V. Kalantar, "Wind energy feasibility study for city of Shahr babak in Iran", Renewable Sustainable Energy Reviews, Vol. 15, No. 6, pp. 2545-2556, 2011

[20] M. H. Baloch, S. A. Abro, G. S. Kaloi, N. H. Mirjat, S. Tahir, M. H. Nadeem, M. Gul, Z. A. Memon, M. Kumar, "A Research on Electricity Generation from Wind Corridors of Pakistan (Two Provinces): A Technical Proposal for Remote Zones", Sustainability, Vol. 9, No. 9, 2017

[21] M. H. Baloch, G. S. Kaloi, Z. A. Memon, "Current scenario of the wind energy in Pakistan challenges and future perspectives: A case study", Energy Reports, Vol. 2, pp. 201-210, 2016

[22] G. S. Kaloi, J. Wang, M. H. Baloch, S. Tahir, "Wind Energy Potential at Badin and Pasni Costal Line of Pakistan", International Journal of Renewable Energy Development, Vol. 6, No. 2, pp. 103-110, 2017

[23] M. H. Baloch, J. Wang, G. S. Kaloi, "A Point of View: Analysis and Investigation of Wind Power from Southern Region of Pakistan", International Journal of Energy Conversion, Vol. 3, No. 3, pp. 103-110, 2015 